\title{
Development of a sampling plan for Myzus persicae (Hemiptera: Aphidoidea) and its predator Macrolophus costalis (Hemiptera: Miridae) on tobacco
}

\author{
Christos G. ATHANASSiOU ${ }^{1}$, Nickolas G. KAVALliERATOS ${ }^{2 *}$, ŽElJKo TOMANOVIĆ ${ }^{3}$, SnežANA TOMANOVIĆ3 \\ and MARIJA MILUTINOVIĆ ${ }^{4}$ \\ ${ }^{1}$ Laboratory of Agricultural Zoology and Entomology, Agricultural University of Athens, 75 Iera Odos str., 11855 Athens, Attica, \\ Greece \\ ${ }^{2}$ Benaki Phytopathological Institute, Department of Entomology and Agricultural Zoology, Laboratory of Agricultural Entomology, \\ 8 Stefanou Delta str., 14561 Kifissia, Attica, Greece \\ ${ }^{3}$ Institute of Zoology, Faculty of Biology, University of Belgrade, Studentski trg 16, 11000 Belgrade, Serbia and Montenegro \\ ${ }^{4}$ Laboratory for Medical Arachnoentomology, Institute for Medical Research, Dr Subotica 4, POB 102, 11129 Belgrade, Serbia and \\ Montenegro
}

Key words. Aphids, Myzus persicae, Miridae, Macrolophus costalis, tobacco, sampling, precision, sample size

\begin{abstract}
A tobacco field in Greece was sampled during the 2001 and 2002 growing seasons to assess the seasonal trends in densities and spatial distributions of the aphid Myzus persicae (Sulzer) and its predatory mirid Macrolophus costalis (Fieber). On repeated occasions between June (just after the transplantation) and September (just before harvest), 20 tobacco leaves (10 from the upper and 10 from the lower plant part) were taken from randomly chosen plants. These leaves were sampled for aphids and mirids. In both years, the highest aphid densities were recorded during July and August, while aphid numbers were low in September. In contrast, the majority of $M$. costalis individuals were found during September when aphid numbers were low. Significantly more $M$. persicae individuals were found in the upper part of the plants, whereas significantly more $M$. costalis individuals were found in the lower part of the plants. As indicated by Taylor's Power Law estimates, both species were aggregated in their spatial distributions among sampling units (leaves). Wilson and Room's model, based on the Taylor's estimates, was used to calculate the mean number of aphids and mirids, from the proportion of sampling units (leaves) that had $>0$ individuals of each species. This model provided a satisfactory fit of the data for both the aphid and the mirid. In addition, Wilson and Room's model was successfully used to predict the mean number of aphids and mirids in a series of samples that were carried out in the same area between June and September 2003 for model validation. Finally, equations are given for the calculation of precision in estimating the mean number of aphids or mirids per sampling unit, and the required sample size for a given level of precision.
\end{abstract}

\section{INTRODUCTION}

Myzus persicae (Sulzer) is the main aphid pest infesting tobacco in Greece (Kavallieratos et al., 2004). It reduces directly both yield and quality of the product (Guthrie et al., 1956; Mistric \& Clark, 1978) and also acts indirectly as a vector of viruses (Kennedy et al., 1962). Furthermore $M$. persicae has developed an insecticide resistance on tobacco (Wolf et al., 1994). However, M. persicae on tobacco is attacked by several predators and parasitoids belonging to the families Coccinellidae (Coleoptera), Miridae (Hemiptera), Berytidae (Hemiptera), Nabidae (Hemiptera), Anthocoridae (Hemiptera), Syrphidae (Diptera), Chrysopidae (Neuroptera), Braconidae (Hymenoptera) (Dimitrov, 1977; Athanassiou et al., 2003; Kavallieratos et al., 2004).

A mirid, Macrolophus costalis (Fieber), is a predator of M. persicae on tobacco (Dimitrov, 1977; Athanassiou et al., 2003) that can develop high population densities (Athanassiou et al., 2003). Furthermore, this predator is considered one of the most abundant predatory species in tobacco fields (Dimitrov, 1977; Athanassiou et al., 2003). Athanassiou et al. (2003) described the seasonal abun- dance and spatial distribution of $M$. costalis on tobacco and investigated its association with population and spatial changes of its prey $M$. persicae. Here we test the value of $M$. costalis as a biocontrol agent in the field against $M$. persicae.

The integration of natural enemy "critical densities" into aphid management programs will reduce insecticidal applications. Theoretically, aphid populations will be suppressed and will not reach economically damaging levels, if rates of predation and parasitism reach a certain threshold (Wilson, 1994). Hence, the development of a reliable sampling plan designed to estimate numbers of both aphids and enemies would encourage farmers to adopt an IPM-based aphid control strategy, which may, under certain circumstances, increase profit. Nevertheless, as yet there are no established aphid and enemy thresholds on tobacco. In our study, we estimated the seasonal trends in density and the associated spatial patterns of $M$. persicae and M. costalis on tobacco. Also, we developed a sampling plan to estimate sizes of aphid and mirid populations, as well as to examine and validate the relationship between aphids and mirids. Our study can serve as a basis for the incorporation of the M. costalis

\footnotetext{
* Corresponding author; e-mail: nick_kaval@hotmail.com
} 
density estimates in an aphid decision-making management.

\section{MATERIAL AND METHODS}

The study was carried out in a tobacco field approx. 1.4 ha in the area of Tithorea (Sterea Hellas, Central Greece), and was completed over two consecutive growing seasons (2001-2002). The experimental field was rectangular and kept free from insecticidal treatments. In this area, as indicated by previous samplings, $M$. persicae was by far the most abundant tobacco pest, and $M$. costalis had high densities. The tobacco variety planted was McNair 944. Leaves were collected from ten randomly chosen tobacco plants, at 10-day intervals, from transplanting in June until just before harvest in September and October. Ten samplings were carried out in each of the two growing seasons. All samplings were conducted between 9.00 and 12.00 am. From each plant, two leaves were taken, one from the upper and one from the lower part of the plant. Each leaf was instantly sealed in a plastic bag and taken to the laboratory for counting and identification of the individuals found. To confirm the identify of all Macrolophus individuals found, nymphs were reared until adult emergence on $M$. persicae infesting artificiallycontaminated seedlings of tobacco.

The presence versus absence of individuals on leaves from the upper and lower parts of the plant were compared by chi-square test (at $P<0.05$ ) for each species in each sampling year. The same procedure was followed also for each sampling occasion (date). In addition, the number of predators was plotted against the number of aphids for individual sampling units (leaves), to indicate the numerical relationship between the two species.

For the two most abundant species, $M$. persicae and $M$. costalis, spatial distribution among sampling units was characterized by using the parameters of Taylor's power law (Taylor, 1961, 1984; Southwood, 1978). This law describes the regression of variance against the mean of the number of individuals per sampling unit (leaf), according to the equation:

$$
\log \left(s^{2}\right)=a+b \log (\bar{x})
$$

where $s^{2}$ is the variance, $\bar{x}$ is the mean, $a$ is the y-intercept and $b$ is the slope of the regression line. This equation can be transformed as follows (Southwood, 1978):

$$
s^{2}=A \bar{x}^{b}
$$

where $A$ is the antilogarithm of $a$ and constitutes a scaling factor dependent on the sampling unit, and $b$ is an index of species spatial pattern, with $b<1, b=1$ and $b>1$ indicating uniform, random and aggregated spatial pattern respectively (Southwood, 1978; Taylor, 1984; Davis, 1994). Also, correlation coefficients ( $r$ ) were calculated, to characterize the goodness-of-fit of Taylor's model. The values of $a, b$ and $r$ were tested for departure from 0,1 and 0 , respectively, using the two-tailed $t$ test at $n-2 d f$ (Snedecor \& Cochran, 1980). The coefficients of Taylor's power law were estimated from the combined counts for both sampling seasons.

To describe the relationship between the proportion $(p)$ of sampling units (leaves) with $>0 M$. persicae or M. costalis individuals and the mean number of individuals per sampling unit, the equation of Wilson \& Room (1983) was used:

$$
p=1-e^{-\bar{x}\left[\left(\ln \left(A \bar{x}^{b-1}\right)\right)\left(\frac{1}{A \bar{x}^{b-1}}-1\right)\right]}
$$

where $A$ and $b$ are Taylor's estimates. This $p-\bar{x}$ equation can be used for predicting the mean number of individuals of a given species per sampling unit $(\bar{x})$ from a simple count of the proportion of sampling units in which this species is present $(p)$. Two $p-\bar{x}$ equations were calculated, one for $M$. persicae and one for
M. costalis, based on $A$ and $b$ estimates for each species. The goodness-of-fit of these equations to the data was estimated by calculating correlation coefficient values for each equation, using a non-linear analysis as suggested by Payne (2002).

The practical utility of these two equations was validated during the 2003 growing season. In this way, we examined if the Wilson and Room's model could be used for a wider range of $p-\bar{x}$ values, in other tobacco fields. Between June and September 2003, samples were taken from 8 predetermined tobacco fields, located in the same cultivation zone (Sterea Hellas, Central Greece), but not close to the field sampled the two previous seasons. The sampling procedure was the same as above, with one exception; there were only 4 sampling occasions for each field. For each sampling occasion and field, the mean number of M. persicae or M. costalis individuals/leaf was calculated $(\bar{x})$, as well as the number of leaves where individuals of these species were present $(p)$. Then, by using the value of $p$ and the above equation, the predicted $\bar{x}$ value was calculated for each case. For each species, the observed mean values were plotted against the predicted mean values, and the correlation coefficient $(r)$ for observed-predicted pairs was calculated. The significance of this coefficient (departure from zero) was examined by using the two-tailed $t$-test, as above.

For the estimation of sample size (the number of leaves required) for a given level of precision, Ruesink and Kogan's equation was used (Ruesink \& Kogan, 1982):

$$
n=\left(\frac{z_{a / 2}}{D}\right)^{2} A \bar{x}^{(b-2)}
$$

where $n$ is the number of sampling units, $D$ is the precision level as a proportion of the mean, $z_{\alpha / 2}$ is the value of $z$ distribution for the desired significance level (in our case $\alpha=0.05$ ), and $A$ and $b$ are Taylor's parameters. This relation was examined for several $D$ levels. In addition, the precision in estimating mean density for a given number of sampling units (20 in our case) was calculated by using the equation:

$$
D=Z_{a / 2} \sqrt{\frac{A \bar{x}^{b-2}}{n}}
$$

which is the previous equation rearranged to solve for $D$ (Ruesink \& Kogan, 1982). As above, D was calculated for several $n$ values.

\section{RESULTS}

\section{Seasonal occurrence and within-plant presence}

The most abundant pest species on any given sampling occasion in both years was generally $M$. persicae: more than $95 \%$ of the total number of pest individuals found belonged to this species. Some thrips (Thysanoptera) and Bemisia tabaci (Gennadius) individuals were also found. Aphid population densities were generally low early in the 2001 season (mid-June), when $<45$ aphids were found per tobacco leaf. Low densities persisted until late July, when $<90$ aphids/leaf were found, with the exception of early July, when $>130$ aphids/leaf were recorded. The highest aphid densities were noted in early August (approx. 290 aphids/leaf), but densities rapidly declined thereafter. At the two last sampling dates (September) aphid densities were especially low $(<3.5$ aphids/leaf). Higher densities occurred in 2002. Early in the season (June 2002) aphid densities were similar to those recorded in 2001, but beginning in early July (when there were $>230$ aphids/leaf) densities remained high until the end of August. As in 2001, the highest densities were 

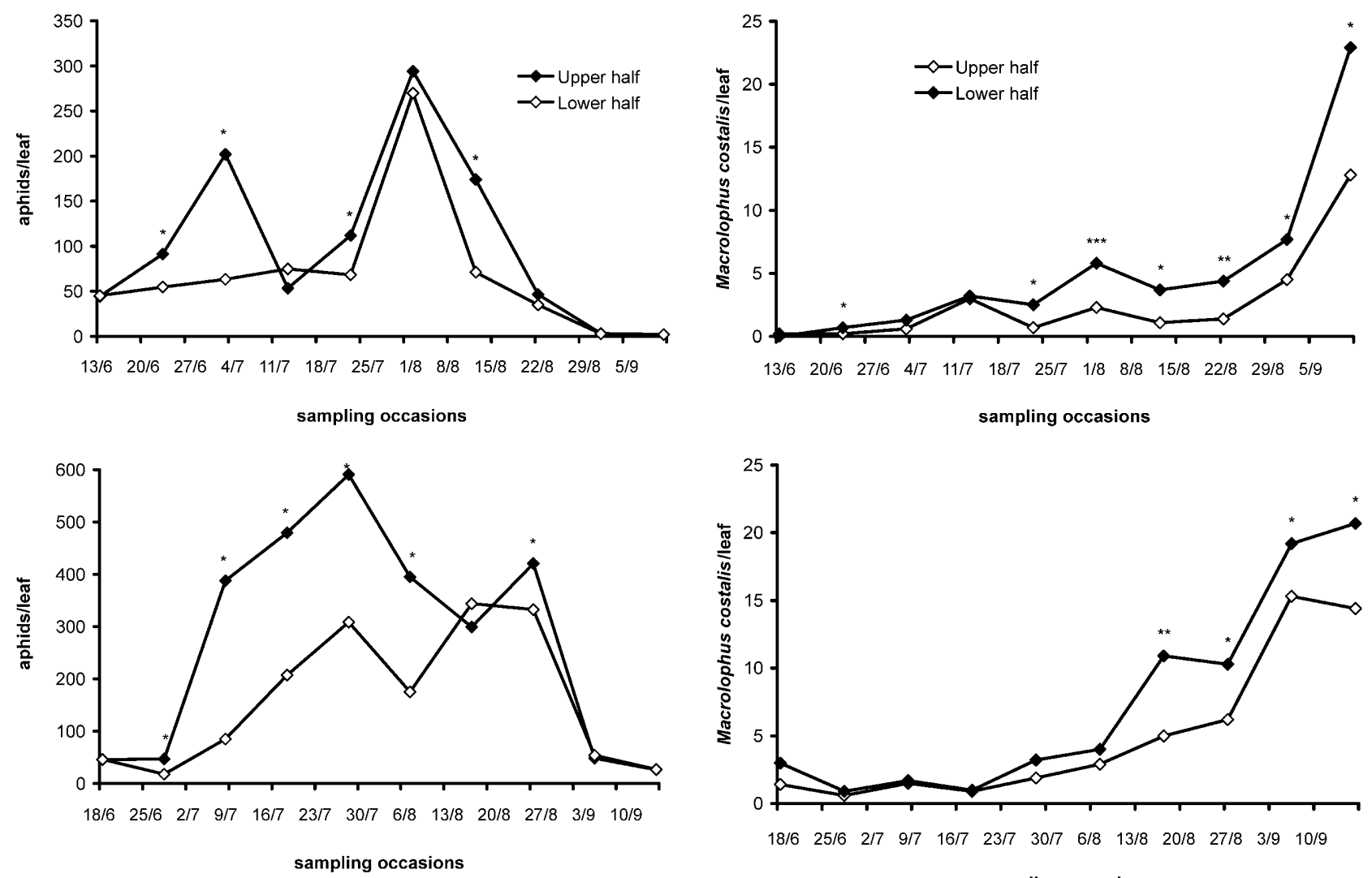

Fig. 1. Mean number of M. persicae individuals per tobacco leaf, in the upper and lower parts of tobacco plants, during the 2001 (top panel) and 2002 (bottom panel) samplings (asterisks indicate sampling dates on which significant differences were noted in $M$. persicae numbers between the upper and the lower parts of plants; chi-square test at $P<0.05$ ).

noted during late July, when aphid numbers reached 450 individuals/leaf. During September, M. persicae densities declined, but aphids were found at considerably higher densities in comparison with the 2001 season.

Very few individuals of $M$. costalis were found early in the season in 2001. Thus, $<1$ M. costalis individual/leaf was found until early July. Mirid densities increased from mid July until late August, and ranged between 1.6 and 4.5 mirids/leaf. However, the highest densities were found during the last sampling (September) when $>17.5$ individuals/leaf were found. Similarly, during 2002, $M$. costalis densiteis were rather stable and low until mid August. High densities were found during the last two samplings (September), when $>17$ mirids/leaf were found.

In both growing seasons, M. persicae occurred significantly more often on leaves in the upper parts of plants than in the lower parts (Fig. 1) (for 2001, $\chi^{2}=4.76, P=$ 0.0290 ; for $2002, \chi^{2}=7.60, P=0.0058$; in both cases $d f$ =1). However, significant differences in $M$. persicae presence between the lower and upper parts of the plants occurred in few sampling occasions in 2001 and 2002 (Fig. 1). Contrary to patterns for M. persicae, M. costalis occurred significantly more often on leaves in the lower parts of plants than in the upper parts (Fig. 2) (for 2001,

TABLE 1. Taylor's parameters for the aphid M. persicae and the predatory mirid, M. costalis (in all cases $n=20$ ).

\begin{tabular}{lcccc}
\hline \multicolumn{1}{c}{ Species } & $A^{1}$ & $a^{2}$ & $b^{3}$ & $r^{4}$ \\
\hline M. persicae & 1.51 & $0.18 \pm 0.29$ & $1.71 \pm 0.23^{* *}$ & $0.97^{* * *}$ \\
M. costalis & 1.90 & $0.28 \pm 0.07^{*}$ & $1.55 \pm 0.13^{* *}$ & $0.95^{* * *}$ \\
\hline
\end{tabular}

${ }^{1}$ Antilogarithm of $a ;{ }^{2} y$-intercept value for Taylor's model ( \pm $\mathrm{SE}) ;{ }^{3}$ slope value for Taylor's model $( \pm \mathrm{SE}) ;{ }^{4}$ correlation coefficient value for goodness-of-fit for Taylor's model; * $a$-values are significantly different from $0(\alpha=0.01$, two-tailed $t$-test); $* *$ $b$-values are significantly different from $1(\alpha=0.01$, two-tailed $t$-test $) ; * * *$-values are significantly different from $0(\alpha=0.01$, two-tailed $t$-test) 

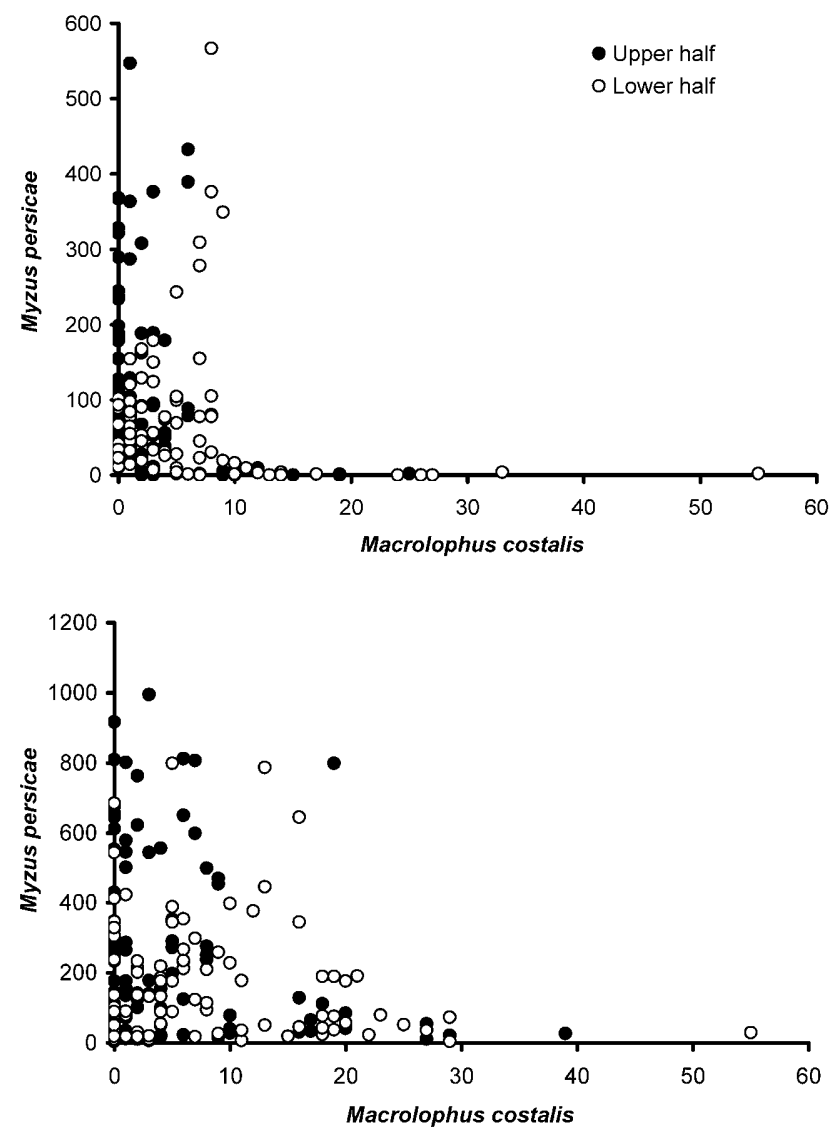

Fig. 3. Relation between the number of $M$. costalis individuals on each tobacco leaf and the respective $M$. persicae numbers on the same leaf, in the upper and lower parts of tobacco plants, during the 2001 (top panel) and 2002 (bottom panel) sampling seasons.

\section{Spatial distribution and $p-\bar{x}$ model}

For both species, the slope $(b)$ values were significantly different from 1 (Table 1). In contrast, the y-intercept values $(a)$ were significantly different from 0 only in the case of $M$. costalis. Finally, for both species, correlation coefficients were significantly greater than 0 at the $\alpha=$ 0.01 level (Table 1).

Equations for the Wilson and Room model (based on $A$ and $b$ values calculated from Taylor's Power Law) are described by hyperbolic curves (Fig. 4; as the mean increases, the corresponding value of $p$ does so also, but at a diminishing rate). According to the $p-\bar{x}$ relation, when $60 \%$ of the sampling units (leaves) contain mirids, the mean number of mirids/ sampling unit is approx. 2 (Fig. $4)$. In the case of aphids, for the same p-value (0.60), the predicted mean is approx. 40 (Fig. 4). For both species, the correlation coefficient $(r)$ for the Wilson and Room model was significantly different from zero, but the $r$-value for $M$. costalis was higher than that for $M$. persicae (for $M$. costalis $r^{2}=0.71$; for $M$. persicae $r^{2}=$ $0.31)$.

As noted above, the equations derived from 2001 and 2002 data were applied to sampling data in 2003 to calculate the mean numbers of aphids and mirids on a leaf. The predicted values were plotted against the observed values,
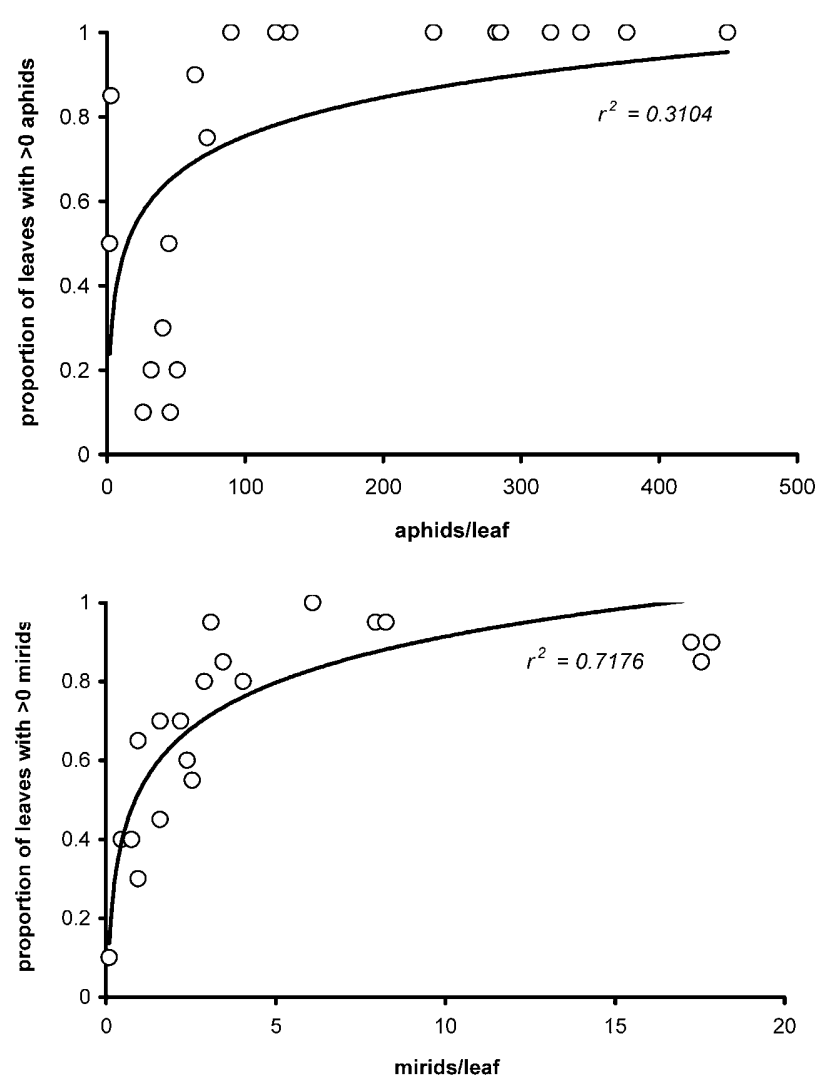

Fig 4. Relation between the proportion of sampling units (leaves) that had one or more (i.e., $>0$ ) individuals of aphids or mirids, and the mean number of aphids or mirids per sampling unit, for M. persicae (top panel) and M. costalis (bottom panel).

as shown in Fig. 5. Based on correlation coefficient values (both positive and significant at $P<0.05$ ), the mean number of $M$. persicae and $M$. costalis could be predicted satisfactorily by using the proportion of sampling units with $M$. persicae or $M$. costalis individuals, according to the Wilson and Room equation.

\section{Precision and sample size}

In all cases, levels of precision ( $D$ values) decrease as the mean increases (Fig. 6). In general, this decrease is more pronounced in the case of $M$. costalis than in $M$. persicae. Precision increases with the number of sampling units. Despite the fact that precision is improved with an increase in the sample size, gains in precision become minor at high sample sizes, especially when $n>$ 10 (Fig. 6). Similarly, the required number of sampling units decreases with an increase in the mean density, as well as with an increase in $D$ (Fig. 7).

\section{DISCUSSION}

According to the results of our study, under the conditions prevailing in the study area, high aphid densities are established in tobacco fields during July, approximately 20-30 days after the transplantation of the plants. Late in the season, just before harvest, $M$. persicae densities declined notably, likely as the result both of densitydependent factors and of the prevailing temperatures. In 

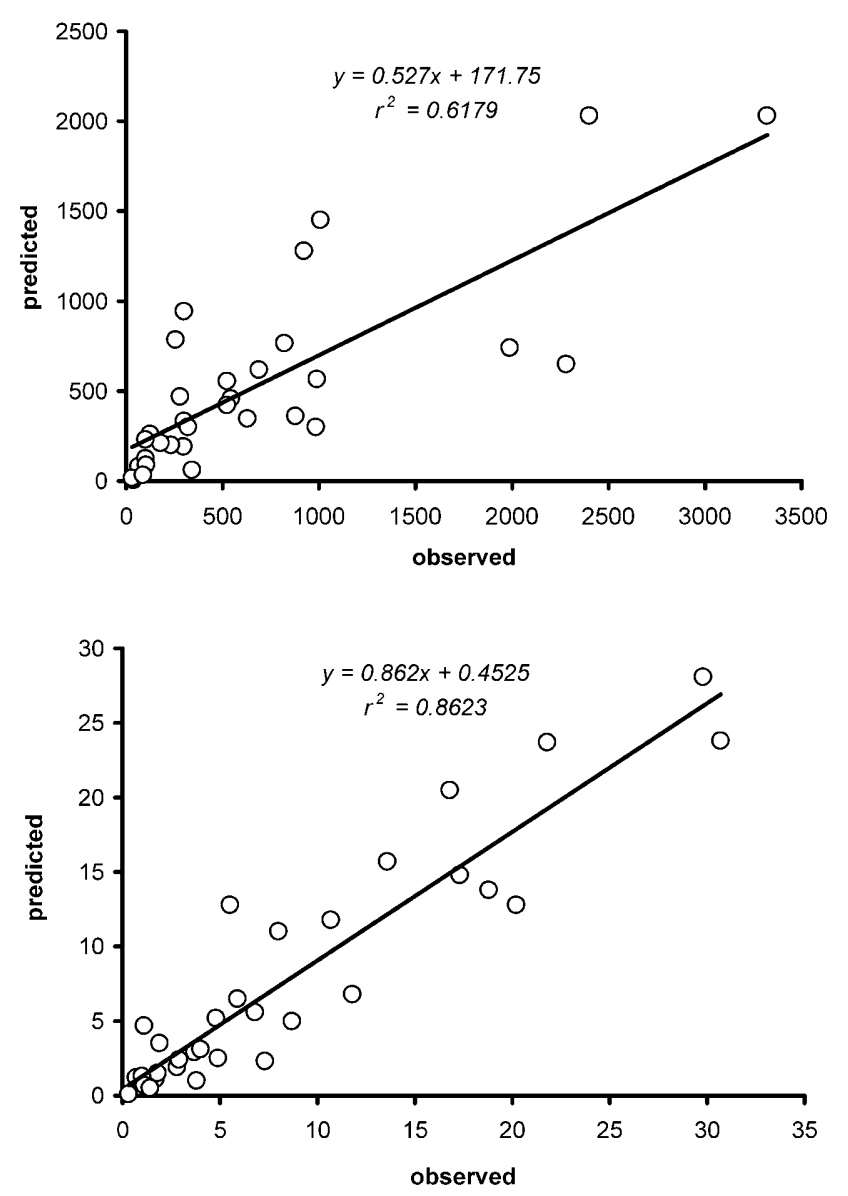

Fig. 5. Relation between the observed and predicted mean densities of $M$. persicae (top panel) and M. costalis (bottom panel) during the 2003 samplings.

contrast, the abundance of $M$. costalis was continuously low during the summer months, and its densities increased only during September, when M. persicae densities were low. These observations are similar to those of Athanassiou et al. (2003). These authors found that although $M$. persicae densities were extremely high during summer, mirid numbers were low, and reached a peak in September, when aphids were scarce. Thus, $M$. costalis densities do not track changes in aphid densities; this may suggest that predator activity is not the main reason for the decline observed in aphid abundance. Macrolophus spp. can feed on several prey items such as aphids, mites, whiteflies, thrips and lepidopteran larvae (Fauvel et al., 1987; Arzone et al., 1990; Alomar et al., 1994; Izquierdo et al., 1994; Sampson \& King, 1996; Montserrat et al., 2000), and these predators develop satisfactorily even in the absence of prey (Lucas \& Alomar, 2001). Hence, the presence of other prey more preferred by $M$. costalis may reduce aphid consumption. This possibility needs further study, as it may negatively affect the efficacy of $M$. costalis against $M$. persicae. .

In addition to these "asynchronous" population trends between mirids and aphids, the two species also differed in their spatial patterns: $M$. persicae was mainly found on the upper leaves, whereas M. costalis was mainly found
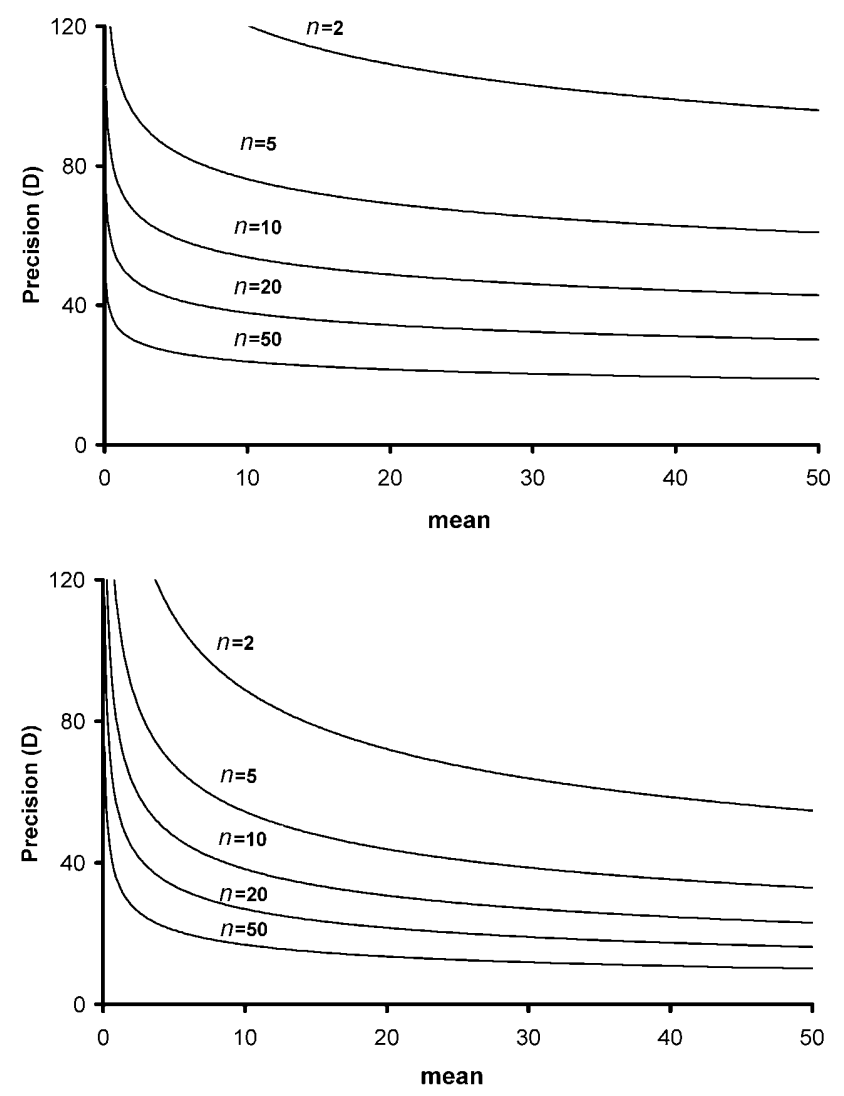

Fig. 6. Changes in the required sample size as a function of mean density, for various precision levels, for M. persicae (top panel) and M. costalis (bottom panel).

on the lower leaves. However, no differences were noted in aphid numbers between the upper and lower parts of the plant, early or late in the season. This could be attributed to the fact that early in the season all leaves on the tobacco plant are new, and late in the season all leaves are senescent; thus, the morphological and compositional characteristics may not vary considerably among leaves during these intervals. There was also no apparent correlation between the number of aphids and mirids occurring in the same sampling unit. In particular, in a noticeable number of sampling units with high aphid numbers the corresponding $M$. costalis numbers were low. Similarly, a number of leaves bearing high numbers of mirids had very few aphids. The diurnal activity of the predator may be responsible for these observations. It is known that some predatory mirids are particularly active during specific times of day, and seek shaded areas in daylight (Sana \& Haq, 1974). Hence, since all samplings were conducted in morning hours, it is possible that insect counts may have underestimated the number of mirids on leaves with high aphid densities.

The lack of spatial coincidence has also been recorded for coccinellids by Wagner \& Ruesink (1982). These authors reported that corn leaf aphids and Hippodamia convergens Guerin were located primarily in the upper part of the plant while the distribution of Coleomegilla maculata (DeGeer) was exclusively limited to the lower plant part. It is now well established that some coccinel- 

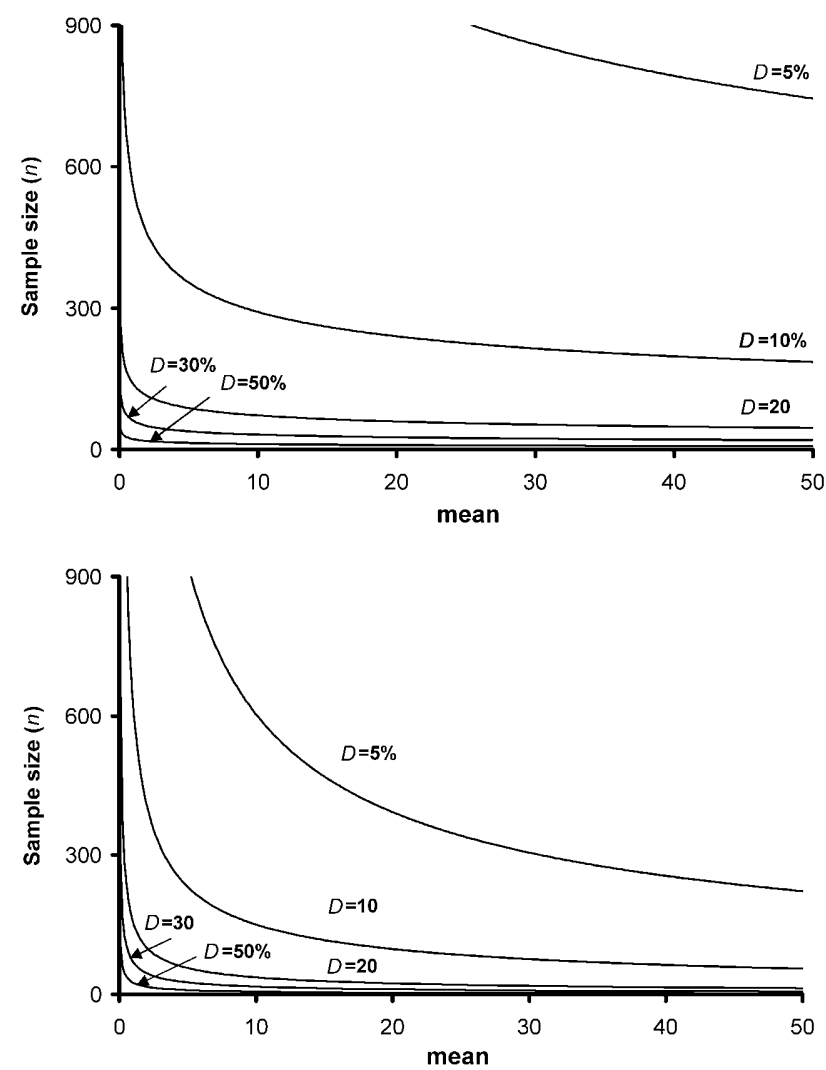

Fig. 7. Changes in the precision level, expressed as a $\%$ fraction of the mean $(D)$, as a function of mean density, for various $\mathrm{n}$ levels, for M. persicae (top panel) and M. costalis (bottom panel).

lids have alternative food sources and this may partially explain the differences between their spatio-temporal distributions and those of aphids (Hodek \& Honěk, 1996). Further experimental work is needed to test this hypothesis.

The high and significant correlation coefficients for Taylor's model are indicative of the strong goodnessof-fit for Taylor's Power Law. Although several models based on the relation between the variance and the mean have been proposed (Karandinos, 1976; Southwood, 1978; Davis, 1994), Taylor's Power Law almost always provides the best fit to the data, confirming its characterization of "Universal Law" (Davis, 1994; Subramanyam \& Hagstrum, 1995; Kapatos et al., 1996). In our study, Taylor's slope $(b)$ values were indicative of an aggregated distribution among sampling units, for both species examined. This aggregation of high numbers of individuals in a relatively low number of sampling units reduces the precision obtained in estimating mean insect density. Determining the proportion of leaves with $>0$ individuals can be considered as an alternative to estimating the mean directly. Thus, if a specific threshold is established based on a given mean density value, this mean can be predicted by simple presence/absence characterizaton of the samples, without counting the individuals found (Wilson \& Room, 1983; Subramanyam \& Hagstrum, 1995). This is important not only for assessing aphid population levels but also for assessing the presence of predators and parasitoids, because these species can be effective biocontrol agents above a specific "threshold" ratio of predator/parasitoid density (Wilson, 1994; Giles et al., 2003). Hence, if this ratio can be accurately predicted from the $p-\bar{x}$ relation, insecticidal applications may not be necessary. This model is not very accurate at high mean density values, but the precision provided is satisfactory for low densities, indicating that early infestations can be accurately predicted. Our validation data suggest that the Wilson and Room model can be used in many cases. The model gave more accurate estimates for $M$. costalis than for $M$. persicae. In the case of the aphids, densities increased dramatically as the growing season progressed, and as a result, most $p$ values were 1 or close to 1 . In contrast, $M$. costalis was absent from a sufficiently large proportion of sampling units, such that sampling provided more data points at low mean values for model validation.

High sample-to-sample variation may also lead to an exponential increase in the sample size required for sufficient precision (Cho et al., 1995; Kapatos et al., 1996; Deligeorgidis et al., 2002). Based on our results, the specific sample size that we used (20 leaves) was rather small to estimate the mean under a very sensitive precision level $(D=10 \%)$, especially at low population densities. Such a sample size may be adequate for high mean values; however, estimating high densities may not be of practical importance. In addition, obtaining a high level of precision level by using a moderate sample size is not feasible, even if high mean values are to be predicted. Generally, a level of $20 \%$ can be considered as an acceptable precision level in pest management (Southwood, 1978; Ruesink \& Kogan, 1982). Because greatly increasing the sample size is not always possible, it is suggested that, at least for M. persicae and M. costalis on tobacco, a sampling plan should rather be based on a fixed sampling size rather than on a fixed precision level. Also, based on the relations shown in Figs 6 and 7, very little is gained by an increase in sample size beyond 10 . According to these equations, for $M$. costalis and for $D=$ $20 \%$ and $\bar{x}=0.5,1,10$ and 50 individuals/leaf, the number of leaves that should be sampled is $242,157,37$ and 13 , respectively. For the same $D$ and mean values, the respective figures for $M$. persicae are 169, 139, 88 and 46 leaves, indicating that a higher number of samples is generally required for this species than for $M$. costalis.

Our study provides information about the seasonal occurrence of $M$. persicae on tobacco leaves, and the concomitant existence of a naturally occurring population of its predator $M$. costalis. We also suggest a sampling plan based on Taylor's estimates, for both species. Sampling is a key element in pest management, especially when beneficial species are present, because their presence should be assessed in relation to the pests' densities. A samplingbased management strategy in tobacco is essential under the establishment of certain thresholds, which can vary among countries, pest species, plant varieties and so forth. The determination of these thresholds would encourage 
tobacco farmers or managers to follow a sampling-based control strategy, under the principles of IPM.

\section{REFERENCES}

Alomar O., Goula M. \& Albajes R. 1994: Mirids for biological control: identification, survey in non-cultivated winter plants and colonization of tomato fields. Bull. IOBC/ WPRS 17: 217-223.

Arzone A., Alma A. \& Tavella L. 1990: Role of Mirids (Rhynchota: Heteroptera) in the control of Thrips tabaci Lindemann (Thysanoptera: Thripidae). Boll. Zool. Agr. Bachic. 22: 43-51.

Athanassiou C.G., Kavallieratos N.G., Ragkou V.S. \& Buchelos C.T. 2003: Seasonal abundance and spatial distribution of the predator Macrolophus costalis Fieber (Heteroptera: Miridae) and its prey Myzus persicae (Sulzer) (Homoptera: Aphidoidea) on tobacco. Phytoparasitica 31: 8-18.

Cho K., Eckel G.S., Walgenbach J.F. \& Kennedy G.G. 1995: Spatial distribution and sampling procedures for Frankliniella spp. (Thysanoptera: Thripidae) in stacked tomato. J. Econ. Entomol. 88: 1658-1665.

DAVIS P.M. 1994: Statistics for describing populations. In Pedigo L.P. \& Buntin G.D. (eds): Handbook of Sampling Methods for Arthropods in Agriculture. CRC Press, Boca Raton, pp. 33-54.

Deligeorgidis P.N., Athanassiou C.G. \& Kavallieratos N.G. 2002: Seasonal abundance, spatial distribution and sampling indices of thrip populations on cotton: a 4 year survey from central Greece. J. Appl. Entomol. 126: 343-348.

Dimitrov A. 1977: A study of the beneficial fauna of Virginia tobacco. Rast. Zashch. 25: 35-38 (in Bulgarian).

Fauvel G., Malausa J.C. \& Kaspar B. 1987: Laboratory studies on the main characteristics of Macrolophus caliginosus Wagner (Heteroptera: Miridae). Entomophaga 32: 529-543.

Giles K.L., Jones D.B., Royer T.A., Elliott C. \& Dean KinDLER S. 2003: Development of a sampling plan in a winter wheat that estimates cereal aphid parasitism and predicts population suppression. J. Econ. Entomol. 96: 975-982.

Guthrie F.E., RabB R.L. \& van Middelem C.H. 1956: Control of aphids on cigar-wrapper and flue-cured tobacco. J. Econ. Entomol. 49: 602-606.

Hodek I. \& HonĚK A. 1996: Ecology of Coccinellidae. Kluwer Academic Publishers, Dordrecht, 464 pp.

IzQuierdo J.I., Solans P. \& Vitalle J. 1994: Parasitoids and predators of Helicoverpa armigera (Hubner) (Lepidoptera: Noctuidae) on table tomato crops. Bol. San. Veg. Plagas 20: 521-530 (in Spanish).

Kapatos E.T., Stratopoulou E.T., Sahinoglou A., Tsitsipis J.A. \& LyCOURESIS D.P. 1996: Development of an optimum sample plan for the population of Aphis gossypii (Homoptera: Aphididae) on cotton in Greece. J. Appl. Entomol. 120: 245-248.

Karandinos M.G. 1976: Optimum sample size and comments on some published formulae. Bull. Entomol. Soc. Am. 22 $417-421$.

Kavallieratos N.G, Athanassiou C.G., Tomanović Ž., PapadoPOUlos G.D. \& VAYIAS B.J. 2004: Seasonal abundance and effect of predators (Coleoptera: Coccinellidae) and parasitoids (Hymenoptera: Braconidae: Aphidiinae) on Myzus persicae
(Hemiptera: Aphidoidea) densities on tobacco: a two-year study from Central Greece. Biologia 59: 613-619.

Kennedy J.S., Day M.F. \& Eastop V.F. 1962: A Conspectus of Aphids as Vectors of Plant Viruses. Commonwealth Institute of Entomology, London, $114 \mathrm{pp}$.

Lucas É. \& Alomar O. 2001: Macrolophus caliginosus Wagner (Heteroptera: Miridae) as an intraguild prey for the zoophytophagous Dicyphus tamaninii Wagner (Heteroptera: Miridae). Biol. Contr. 20: 147-152.

Mistric W.J.J.R. \& ClaRK G.B. 1978: Green peach aphid injury to flue-cured tobacco leaves. Tob. Sci. 23: 23-24.

Montserrat M., Albajes R. \& Castañé C. 2000: Functional response of four Heteropteran predators preying on greenhouse whitefly (Homoptera: Aleurodidae) and western flower thrips (Thysanoptera: Thripidae). Environ. Entomol. 29: 1075-1082.

PAYNE R.W. 2002: Genstat ${ }^{\circledR}$ for Windows $^{\mathrm{TM}}$ : Introduction. Lawes Agricultural Trust, Rothamsted, $276 \mathrm{pp}$.

RuesinK W.G. \& Kogan M. 1982: The quantitative basis of pest management: sampling and measuring. In Metcalf R.L. \& Luckmann W.H. (eds): Introduction to Insect Pest Management. Wiley, New York, pp. 315-352.

SAMPson A.C. \& KInG V.J. 1996: Macrolophus caliginosus Wagner (Heteroptera: Miridae), field establishment and pest control effect in protected tomatoes. Bull. OILB/WPRS 19: $143-146$.

SANA D.L. \& HAQ M.T. 1974: Feeding intensity of the tea mosquito bug during daily rhythm-I. Tea J. Bangl. 1974(10): $7-11$.

Southwood T.R.E. 1978: Ecological Methods with Particular Reference to the Study of Insect Populations. John Wiley \& Sons, New York, 524 pp.

Snedecor G.W. \& Cochran W.G. 1980: Statistical Methods. Iowa State University Press, Ames, 415 pp.

Subramanyam B. \& Hagstrum D.W. 1995: Sampling. In Subramanyam B. \& Hagstrum D.W. (eds): Integrated Management of Insects in Stored Products. Marcel Dekker, New York, pp. 142-188.

TAYLOR L.R. 1961: Aggregation, variance and the mean. Nature 189: 732-735.

TAYLOR L.R. 1984: Assessing and interpreting spatial distribution of insect populations. Annu. Rev. Entomol. 29: 321-357.

WAGNER S.W. \& RUESINK W.G. 1982: The distribution of natural enemies of the corn leaf aphid (Homoptera: Aphididae) on field corn. Great Lakes Entomol. 15: 153-157.

WILSON L.T. 1994: Estimating abundance, impact and interactions among arthropods in cotton agroecosystems. In Pedigo L.P. \& Buntin G.D. (eds): Handbook of Sampling Methods for Arthropods in Agriculture. CRC Press, Boca Raton, pp. 475-514.

WILSON L.T. \& Room P.M. 1983: Clumping patterns of fruit and arthropods in cotton, with implications for binomial sampling. Environ. Entomol. 12: 50-54.

Wolf M.A., Abdel-Aal Y.A.I., Goh D.K.S., Lampert E.P. \& Roe M. 1994: Organophosphate resistance in the tobacco aphid (Homoptera: Aphididae): purification and characterization of a resistance-associated esterase. J. Econ. Entomol. 87: $1157-1164$.

Received September 10, 2004; revised April 11, 2005; accepted June 6, 2005 